University of Nebraska - Lincoln

DigitalCommons@University of Nebraska - Lincoln

\title{
Factors Influencing Movement Probabilities of Big Brown Bats (Eptesicus fuscus) in Buildings
}

Laura E. Ellison

U.S. Geological Survey, Biological Resources Discipline, Fort Collins Science Center, Fort Collins, Colorado

Thomas J. O'Shea

U.S. Geological Survey, Biological Resources Discipline, Fort Collins Science Center, Fort Collins, Colorado

Daniel J. Neubaum

Colorado State University, Fort Collins, Colorado

Richard Bowen

Colorado State University, Fort Collins, Colorado

Follow this and additional works at: https://digitalcommons.unl.edu/usgsstaffpub

Part of the Earth Sciences Commons

Ellison, Laura E.; O'Shea, Thomas J.; Neubaum, Daniel J.; and Bowen, Richard, "Factors Influencing Movement Probabilities of Big Brown Bats (Eptesicus fuscus) in Buildings" (2007). USGS Staff -Published Research. 40.

https://digitalcommons.unl.edu/usgsstaffpub/40

This Article is brought to you for free and open access by the US Geological Survey at DigitalCommons@University of Nebraska - Lincoln. It has been accepted for inclusion in USGS Staff -- Published Research by an authorized administrator of DigitalCommons@University of Nebraska - Lincoln. 


\title{
FACTORS INFLUENCING MOVEMENT PROBABILITIES OF BIG BROWN BATS (EPTESICUS FUSCUS) IN BUILDINGS
}

\author{
Laura E. Ellison, ${ }^{1,3}$ Thomas J. O'Shea, ${ }^{1}$ Daniel J. Neubaum, ${ }^{2}$ and Richard A. Bowen ${ }^{2}$ \\ ${ }^{1}$ U.S. Geological Survey, Biological Resources Discipline, Fort Collins Science Center, Fort Collins, Colorado 80526 USA \\ ${ }^{2}$ Department of Biomedical Sciences, Colorado State University, Fort Collins, Colorado 80526 USA
}

\begin{abstract}
We investigated movements of female big brown bats (Eptesicus fuscus) roosting in maternity colonies in buildings in Fort Collins, Colorado (USA), during the summers of 2002, 2003, and 2005. This behavior can be of public health concern where bats that may carry diseases (e.g., rabies) move among buildings occupied by people. We used passive integrated transponders (PIT tags) to mark individual bats and hoop PIT readers at emergence points to passively monitor the use of building roosts by marked adult females on a daily basis during the lactation phase of reproduction. Multi-strata models were used to examine movements among roosts in relation to ambient temperatures and ectoparasite loads. Our results suggest that high ambient temperatures influence movements. Numbers of mites (Steatonyssus occidentalis) did not appear to influence movements of female bats among building roosts. In an urban landscape, periods with unusually hot conditions are accompanied by shifting of bats to different buildings or segments of buildings, and this behavior may increase the potential for contact with people in settings where, in comparison to their more regularly used buildings, the bats may be more likely to be of public concern as nuisances or health risks.
\end{abstract}

Key words: $\quad$ big brown bats; ectoparasites; Eptesicus fuscus; movements; multi-strata models; PIT tags; Program MARK; Steatonyssus occidentalis; survival; temperature.

\section{INTRODUCTION}

The big brown bat (Eptesicus fuscus; see Plate 1) is a common and wide-ranging North American species often implicated in potential exposures of humans to rabies (Mondul et al. 2003). In Colorado, such potential exposures commonly occur in summer around buildings in cities and towns (Pape et al. 1999) when female big brown bats form maternity colonies (Kurta and Baker 1990) or roosts (Kunz and Reynolds 2003). Individuals in maternity colonies will often switch roosts and even transport young to alternate locations during the critical lactation period (Mayrberger 2003), thereby potentially contacting people from several buildings and increasing the risk for disease exposure. Therefore, selection of building roosts that maximize reproductive success and survival while minimizing the negative effects of moving are likely critical to bat populations (Racey 1982, Brigham and Fenton 1986, Williams and Brittingham 1997), and important to our understanding of contact between bats and people.

Many factors may govern choice of and movement among roosting sites by bats. Individuals of many bat species switch roost sites from day to day (Kunz and Lumsden 2003) possibly because of disturbance, predator avoidance, foraging ecology, avoidance of ectoparasite infestations, social behavior, climate (both micro-

Manuscript received 23 February 2006; revised 3 July 2006; accepted 10 July 2006. Corresponding Editor: J. M. Marzluff.

3 E-mail: laura_ellison@usgs.edu and macroclimate), and structural conditions of the roost (see Lewis [1995] for a review). However, probabilities and variances associated with roost switching in relation to these potential factors have never been estimated. Willis and Brigham (2004) investigated roost switching in tree-roosting big brown bats in relation to social cohesion in the northern part of this species' range. They concluded that roost switching in forests might reflect the maintenance of long-term social relationships between individuals from a colony that alternates roosting among a number of different trees. Lewis (1996) conducted a field study that investigated roost switching in relation to two of the environmental as opposed to behavioral factors, temperature and ectoparasites. Based on daily radiotelemetry, she reported that individual pallid bats (Antrozous pallidus) with higher ectoparasite loads switched roosts most often, but that changes in roost use did not appear to be in response to daily changes in temperature.

In 2001, we initiated a study of the ecology of rabies transmission in big brown bats roosting in buildings in the city of Fort Collins, Colorado, where females choose to roost in buildings of various structural types, many of which are occupied by humans. We used the relatively new technology of passive integrated transponders (PIT tags) as a means of marking individuals and hoop-style PIT readers to passively monitor the use of buildings on a continuous basis. We apply multi-strata modeling techniques (Hestbeck et al. 1991, Brownie et al. 1993) to mark-recapture data from PIT-tagged females during 
three summers to investigate two factors that have been proposed to influence frequent roost switching: temperature and ectoparasite intensities (Lewis 1995, 1996). We hypothesized that high ambient temperatures would influence the probabilities of moving to new building locations. We specifically asked whether a bat's propensity to move roosts was affected by the previous day's maximum temperature. We also hypothesized that greater ectoparasite loads would lead to increased movement probabilities.

\section{Methods \\ Study sites and data collection}

During the summers of 2001-2004, we located buildings in Fort Collins that were being used by big brown bats through a combination of radiotelemetry and citizen knowledge (O'Shea et al. 2004). We chose two of these building sites to investigate movement rates of lactating big brown bats. These two specific sites were chosen based on logistic considerations such as equipment needs, accessibility to exit and entry points, and cooperation with the building owners. The HFA site is a large office building and recreational center where bats roost primarily within concrete block walls and use multiple emergence points in cracks behind metal drainpipes. We determined that bats most frequently used four exit points based on nightly emergence counts and previous capture events. We designated these exit points as: northeast (NE), northwest (NW), southeast (SE), and southwest (SW). North to south locations were separated by approximately $15 \mathrm{~m}$, whereas east to west locations were about $20 \mathrm{~m}$ apart. Individuals using a particular emergence point were assumed to be roosting in walls near the drainpipe during the day, and movement within the roost was assumed to be minimal (roosting areas accessed by the four exit points were structurally separated from each other and daily PIT reader records indicated bats roosting in a location emerged from that same location the following evening to forage). The LST site is a complex of three distinct buildings, A, B, and $\mathrm{C}$. The A building is a mobile home and bats roost in a bat box erected on the south side of the structure. Both $\mathrm{B}$ and $\mathrm{C}$ are small one-story houses where bats roost in the attics; the emergence point for $\mathrm{B}$ is on the southwest corner of the roof and the emergence for $\mathrm{C}$ is located on the northwest corner. The distance from $\mathrm{A}$ to $\mathrm{B}$ is approximately $15 \mathrm{~m}$ and the distance between $B$ and $C$ is about $24 \mathrm{~m}$.

At the HFA site, we installed circular hoop activating antennas (NEMA readers; AVID Inc., Norco, California, USA) at the four emergence points for three summers (2002, 2003, and 2005) and at LST, we installed circular hoop readers at the three emergence points for two summers (2003 and 2005). We placed PIT reader hoops over structural gaps and openings where bats typically crawled through them upon emerging or entering. A $12-\mathrm{V}$ battery-powered data logger was attached to each hoop antenna as part of the NEMA reader system. These data loggers stored the date, time, and identification number for each individual detected, and those data were downloaded to a laptop computer several times a week.

We restricted our investigation of movements at these two building sites to approximately two-week periods in 2002, 2003, and 2005 when adult females were at one stage of reproduction (lactating), all PIT readers were working simultaneously on a daily basis, and juveniles were not yet volant. The period of lactation is a particularly critical time to assess factors influencing movement because it entails costs and risks associated with transporting young. The data set was also restricted to those bats that were captured and sampled at the beginning and end of the two weeks to verify reproductive status and to count parasites (see O'Shea et al. [2004] and Wimsatt et al. [2005] for details on capture, marking, and collection of biological samples). We counted the number of ectoparasites (mites of the species Steatonyssus occidentalis; see Plate 1) on standardized portions of the wing and body of each bat. This ectoparasite is the most abundant parasite of big brown bats and is a blood feeder that lives in the roost when not feeding (Dood 1987). We assumed that prevalence of this particular parasite on bat bodies directly correlated with the level of infestation in the roost. We released marked bats near the roost within six hours of capture. We then passively monitored these bats with the installed PIT readers on a daily basis for the two weeks post-capture. There appeared to be no short-term effect of capture and handling; all of the bats processed were detected with PIT readers the morning following capture as they returned from foraging. The Institutional Animal Care and Use Committees at Colorado State University and the U.S. Geological Survey, Fort Collins, Colorado, USA approved all procedures.

We downloaded hourly temperature readings from the Fort Collins Weather Station at Colorado State University to determine maximum ambient temperatures on a daily basis (data available online). ${ }^{4}$ For the two-week period investigated in 2002, maximum daily temperatures ranged from $25.9^{\circ} \mathrm{C}$ to $34.8^{\circ} \mathrm{C}(x=31.3 \pm$ 2.9 ; mean $\pm \mathrm{SD})$. In 2003 , the range was $15.1-29.1^{\circ} \mathrm{C}(x$ $=24.7 \pm 4.1)$, and in 2005 , the range was $15.7-32.4^{\circ} \mathrm{C}(x$ $=28.3 \pm 4.1$ ).

\section{Multi-strata model, encounter histories, and candidate models}

We used the multi-strata (also called multi-state mark-recapture) model in Program MARK to analyze our mark-recapture data (White and Burnham 1999; software available online $){ }^{5}$ The multi-strata model of Brownie et al. (1993) and Hestbeck et al. (1991) is an extension of the Cormack-Jolly-Seber (CJS; Cormack

\footnotetext{
${ }^{4}$ 〈http://ccc.atmos.colostate.edu/ autowx/fclwx_access. php $\rangle$

${ }^{5}\langle$ http://www/phidot.org/software/mark/docs/book/ $\rangle$
} 
TABLE 1. Parameter combinations used in modeling capture and movements of lactating big brown bats (Eptesicus fuscus) at both HFA and LST buildings in Fort Collins, Colorado, USA.

\begin{tabular}{lc}
\hline \hline \multicolumn{1}{c}{ Model description } & Parameters \\
\hline $\begin{array}{l}\text { General multistate model (survival constant over time and strata, } \\
\text { capture and movements differed by time and strata) }\end{array}$ & $S() p.(s \times t) \Psi(s \times t)$ \\
Capture & $p()$. \\
$\quad$ Constant over time and strata & $p(s)$ \\
Constant over time, but differed by strata & $p(s \times t)$ \\
Differed by time and strata & $\Psi()$. \\
Movement & $\Psi(s)$ \\
Constant over time and strata & $\Psi(s+$ MaxTemp) \\
Constant over time, but differed by strata & $\Psi(s+$ Steat $)$ \\
Differed by strata and were a function of maximum ambient temperature \\
Differed by strata and were a function of number of Steatonyssus occidentalis \\
ectoparasite counts & $\Psi(s+$ MaxTemp + Steat $)$ \\
Differed by strata and were a function of maximum ambient temperature & \\
$\quad$ and number of $S$. occidentalis ectoparasite counts &
\end{tabular}

Notes: Survival was always modeled as constant across time and strata. Model nomenclature follows the format suggested by Lebreton et al. (1992).

1964, Jolly 1965, Seber 1965) live recapture model. In addition to survival and capture probabilities, this model allows consideration of movement probabilities among strata. Strata can be geographic areas, specific locations, or physiological states (e.g., age, reproductive status). In our study, strata or state refer to the different roosting locations of the bats. Specifically, the four emergence points at the HFA site were the different strata and at the LST site, strata were the three distinct buildings. Parameters of interest in the multi-strata model are survival, $S$, capture probability, $p$, and transition (movement) probability, $\Psi$. We define survival $(S)$, capture $(p)$, and transition or movement $(\Psi)$ probabilities as follows:

$$
\begin{aligned}
S_{i \mathrm{~A}}= & \text { the probability that a bat alive in stratum A } \\
& \text { during time } i \text { survives until time } i+1 \\
p_{i \mathrm{~A}}= & \text { the probability that a bat present in stratum A } \\
& \text { during day } i \text { is observed during that day } \\
\Psi_{i \mathrm{AB}}= & \text { the probability that a bat roosting in stratum A } \\
& \text { during day } i \text { moves to stratum B on day } i+1, \\
& \text { given that the bat survives from } i \text { to } i+1 .
\end{aligned}
$$

We made the following specific assumptions: (1) timeand stratum-specific capture and movement probabilities are the same for all PIT-tagged bats found in a particular stratum and in a particular sampling period (day); (2) bats behave independently with respect to capture probability, survival, and movement; (3) marked bats do not lose their marks (PIT tags); (4) all bats move instantaneously (in our case, bats leave the roost to forage between 20:00-20:30 hours every evening and return the following morning to a new roost location between 05:00-06:00 hours to begin day roosting); (5) losses to the population through emigration are permanent. Colonial bats are likely to not behave independently with respect to capture probability, survival, and movement. Therefore, we used quasi- likelihood model selection methods to adjust for this lack of independence. PIT tag loss was assumed to be minimal for the two-week period investigated and based on a pilot study where bats were double-marked with freeze branding and there was less than $0.5 \%$ tag loss (L. E. Ellison, T. J. O'Shea, D. J. Neubaum, and R. A. Bowen, unpublished data).

We created separate encounter history files for each year and for each of the two sites. For the HFA site, we coded for every day as either $\mathrm{A}=\mathrm{NE}, \mathrm{B}=\mathrm{NW}, \mathrm{C}=\mathrm{SE}$, or $\mathrm{D}=\mathrm{SW}$ strata depending on which PIT reader hoop detected the bat, or as " 0 " (not captured). The LST location included three strata: A, B, and C. We created three encounter history files for HFA (2002, 2003, and 2005) and two for LST (2003 and 2005). Dates of capture and subsequent monitoring with PIT readers varied by year and site, but were generally consistent across years and were between 12 June and 3 July (HFA, 15-28 June 2002, 12-28 June 2003, and 13-29 June 2005; LST, 19 June-3 July 2003 and 16 June-1 July 2005). The number of lactating individuals captured also varied by year and site with more individuals captured and used for analyses at HFA than at LST (HFA, $N=42$ in 2002, $N=61$ in 2003, $N=77$ in 2005; LST, $N=26$ in 2003, $N=$ 38 in 2005). The total number of bats marked with PIT tags at HFA in 2002 during the two-week period was 53, 68 in 2003, and 91 in 2005. At LST, the total number of bats marked during the two weeks was 31 in 2003 and 47 in 2005. Although we did not determine population size at these two sites, emergence counts were conducted each year before juveniles were volant and we estimated the number of bats at HFA to be approximately 200 individuals and 50 individuals at LST.

We defined a set of a priori candidate models to run in Program MARK for each year and site (Table 1). Based on previous analyses of short-term survival in female big brown bats, we assumed that short-term survival was constant over the two-week period and would not differ 
TABLE 2. Results from Program MARK for modeling capture and movement probabilities of adult, lactating big brown bats (Eptesicus fuscus) roosting in four sites of the HFA building in Fort Collins, Colorado, USA, during two-week periods of summers 2002, 2003, and 2005.

\begin{tabular}{|c|c|c|c|c|c|c|c|c|c|c|c|c|}
\hline \multirow[b]{2}{*}{ Model } & \multicolumn{4}{|c|}{$2002 \dagger$} & \multicolumn{4}{|c|}{$2003 \$$} & \multicolumn{4}{|c|}{$2005 \S$} \\
\hline & $\mathrm{QAIC}_{\mathrm{c}}$ & $\Delta \mathrm{QAIC}_{\mathrm{c}}$ & $\begin{array}{l}\text { QAIC }_{c} \\
\text { weight }\end{array}$ & $K$ & $\mathrm{QAIC}_{\mathrm{c}}$ & $\Delta \mathrm{QAIC}_{\mathrm{c}}$ & $\begin{array}{l}\text { QAIC }_{c} \\
\text { weight }\end{array}$ & $K$ & $\mathrm{QAIC}_{\mathrm{c}}$ & $\Delta \mathrm{QAIC}_{\mathrm{c}}$ & $\begin{array}{l}\text { QAIC }_{c} \\
\text { weight }\end{array}$ & $K$ \\
\hline$\Psi(s+$ MaxTemp $)$ & 970.86 & 0.00 & 0.74 & 15 & 1515.23 & 1.58 & 0.17 & 18 & 1399.08 & 0.00 & 0.62 & 18 \\
\hline$\Psi(s+$ MaxTemp + Steat $)$ & 973.02 & 2.16 & 0.25 & 16 & 1515.50 & 1.85 & 0.15 & 19 & 1400.06 & 0.97 & 0.38 & 19 \\
\hline$\Psi(s)$ & 979.73 & 8.87 & 0.01 & 14 & 1513.65 & 0.00 & 0.37 & 17 & 1416.16 & 17.08 & 0.00 & 17 \\
\hline$\Psi(s+$ Steat $)$ & 981.86 & 11.00 & 0.00 & 15 & 1513.97 & 0.32 & 0.32 & 18 & 1416.79 & 17.70 & 0.00 & 18 \\
\hline$\Psi()$. & 1069.19 & 98.33 & 0.00 & 3 & 1563.44 & 49.80 & 0.00 & 6 & 1613.16 & 214.07 & 0.00 & 6 \\
\hline$\Psi(s \times t)$ & 1322.56 & 351.70 & 0.00 & 208 & 1879.93 & 366.28 & 0.00 & 224 & 1599.16 & 200.08 & 0.00 & 257 \\
\hline
\end{tabular}

Notes: For each model, we list the model name, the Akaike Information Criterion corrected for overdispersion $(\mathrm{QAIC})$, the $\Delta$ QAIC $_{\mathrm{c}}, \mathrm{QAIC}_{\mathrm{c}}$ weight, and number of parameters $(K)$. The model with the lowest $\mathrm{QAIC}_{\mathrm{c}}$ is in boldface type. Survival was considered to be constant across time and strata for the two-week period, and capture probabilities were modeled differently each year.

$\dagger N=42$; dates were $15-28$ June $2002 ; \hat{c}=1.18$. Capture probability was modeled as constant across time and strata, $p($.$) .$

$\$ N=61$; dates were $12-28$ June $2003 ; \hat{c}=1.12$. Capture probability was modeled as constant over time, but different among strata, $p(s)$.

$\S N=77$; dates were 13-29 June 2005; $\hat{c}=1.27$. Capture probability was modeled as different by time and strata, $p(s \times t)$.

by a particular stratum (O'Shea et al. 2004, Wimsatt et al. 2005). Therefore, our global model was one that included a constant rate of survival over time and strata, and capture and movements differed by time and strata. We ran the global model first, and then constrained capture probabilities to be either constant over time and strata, different for each stratum, or different on a daily basis. We then examined movement probabilities and ran five different constrained models by including the maximum daily ambient temperatures and the number of $S$. occidentalis mites counted per individual as covariates (see Table 1). We used the logit link and the alternative optimization (simulated annealing) procedures in MARK to reach numerical convergence.

The fit of these competing models was assessed using the information-theoretic approach (Burnham and Anderson 2002). We estimated overdispersion using median $\hat{c}$ in Program MARK and we selected the most parsimonious models using a combination of $\mathrm{QAIC}_{\mathrm{c}}$ (Akaike's Information Criterion corrected for overdispersed data and small sample sizes), $\Delta \mathrm{QAIC}_{\mathrm{c}}$, and
QAIC $_{\mathrm{c}}$ weights (Burnham and Anderson 2002). We also examined the confidence intervals around the beta $(\beta)$ estimates for both ectoparasites and maximum temperature. If the $95 \%$ confidence intervals for $\hat{\beta}$ did not include 0 , we considered this as additional support that the covariate had an effect on movement probabilities.

\section{RESUlts}

Bats moved most on hot days, as implied by both model-ranking results and the $\beta$ estimates at HFA and LST for all years (Tables 2 and 3). Our model selection procedures gave highest rank to the model with movement probabilities differing by roost location (strata) and varying with the maximum ambient temperatures for both sites during all years except HFA in 2003. High temperatures on a daily basis generally explained more of the variation in movements than models that included only differences among the strata or time. Models including ectoparasites as a covariate were ranked lower in the model set and were usually $>10 \Delta \mathrm{QAIC}_{\mathrm{c}}$ from the best model.

TABLE 3. Results from Program MARK for modeling capture and movement probabilities of adult, lactating big brown bats (Eptesicus fuscus) roosting in the three buildings at LST site in Fort Collins, Colorado, USA, during two-week periods of summers 2003 and 2005.

\begin{tabular}{|c|c|c|c|c|c|c|c|c|}
\hline \multirow[b]{2}{*}{ Model } & \multicolumn{4}{|c|}{$2003 \dagger$} & \multicolumn{4}{|c|}{$2005 \ddagger$} \\
\hline & $\mathrm{QAIC}_{\mathrm{c}}$ & $\Delta \mathrm{QAIC}_{\mathrm{c}}$ & QAIC $_{c}$ weight & $K$ & $\mathrm{QAIC}_{\mathrm{c}}$ & $\Delta \mathrm{QAIC}_{\mathrm{c}}$ & QAIC $_{c}$ weight & $K$ \\
\hline$\Psi(s+$ MaxTemp $)$ & 351.19 & 0.00 & 0.64 & 11 & 912.44 & 0.00 & 0.67 & $\overline{11}$ \\
\hline$\Psi(s+$ MaxTemp + Steat $)$ & 352.40 & 1.21 & 0.35 & 12 & 914.62 & 2.19 & 0.33 & 12 \\
\hline$\Psi(s)$ & 360.63 & 9.44 & 0.01 & 10 & 916.76 & 4.31 & 0.08 & 10 \\
\hline$\Psi(s+$ Steat $)$ & 362.32 & 11.13 & 0.00 & 11 & 918.93 & 6.49 & 0.02 & 11 \\
\hline$\Psi()$. & 375.64 & 24.44 & 0.00 & 5 & 937.72 & 25.28 & 0.00 & 5 \\
\hline$\Psi(s \times t)$ & 626.81 & 275.62 & 0.00 & 127 & 1258.38 & 345.93 & 0.00 & 136 \\
\hline
\end{tabular}

Notes: For each model, we list the model name, the Akaike Information Criterion corrected for overdispersion $\left(\mathrm{QAIC}_{\mathrm{c}}\right)$, the $\triangle$ QAIC $_{\mathrm{c}}, \mathrm{QAIC}_{\mathrm{c}}$ weight, and number of parameters $(K)$. The model with the lowest $\mathrm{QAIC}_{\mathrm{c}}$ is in boldface. Survival was considered to be constant across strata and time for the two-week period, and capture probability differed by strata for each year.

$\dagger N=26$; dates were 19 June-3 July $2003 ; \hat{c}=1.86$.

$\ddagger N=38$; dates were 16 June-1 July $2005 ; \hat{c}=1.19$. 
TABLE 4. Means, standard deviations (or errors), and estimates of $\hat{\beta}$ for the environmental covariate, MaxTemp (high daytime ambient temperature), and the individual covariate, number of $S$. occidentalis (Steat), used to model movement probabilities of adult, lactating big brown bats (Eptesicus fuscus) roosting at the HFA and LST buildings in Fort Collins, Colorado, USA, during two-week periods of summers 2002, 2003, and 2005.

\begin{tabular}{|c|c|c|c|c|c|c|c|}
\hline \multirow[b]{2}{*}{ Building } & \multirow[b]{2}{*}{ Year } & \multicolumn{3}{|c|}{ MaxTemp } & \multicolumn{3}{|c|}{ Steat } \\
\hline & & $\bar{x} \pm \mathrm{SD}$ & $\hat{\beta}$ & $95 \% \mathrm{CI}$ & $\bar{x} \pm \mathrm{SE}$ & $\hat{\beta}$ & $95 \%$ CI \\
\hline HFA & $\begin{array}{l}2002 \\
2003 \\
2005\end{array}$ & $\begin{array}{l}31.2 \pm 3.0 \\
23.1 \pm 3.4 \\
28.1 \pm 4.3\end{array}$ & $\begin{array}{l}0.12 \\
0.02 \\
0.09\end{array}$ & $\begin{array}{r}0.05-0.20 \\
-0.02-0.06 \\
0.02-0.14\end{array}$ & $\begin{array}{l}57.4 \pm 60.3 \\
67.1 \pm 49.0 \\
38.6 \pm 17.6\end{array}$ & $\begin{array}{r}-0.01 \\
0.08 \\
-0.08\end{array}$ & $\begin{array}{l}-0.20-0.18 \\
-0.03-0.19 \\
-0.22-0.0\end{array}$ \\
\hline LST & $\begin{array}{l}2003 \\
2005\end{array}$ & $\begin{array}{l}24.5 \pm 5.0 \\
29.8 \pm 1.7\end{array}$ & $\begin{array}{l}0.13 \\
0.23\end{array}$ & $\begin{array}{l}0.05-0.20 \\
0.04-0.44\end{array}$ & $\begin{array}{l}3.8 \pm 6.7 \\
6.8 \pm 6.1\end{array}$ & $\begin{array}{r}0.10 \\
-0.01\end{array}$ & $\begin{array}{l}-0.18-0.39 \\
-0.31-0.29\end{array}$ \\
\hline
\end{tabular}

The effect of high temperatures on movements of bats differed among the three years investigated. The confidence intervals around the $\beta$ estimates for maximum temperature at HFA did not include 0 in 2002 and 2005, but did in 2003 (Table 4). In 2003, there was little evidence of an effect of high ambient temperatures on movements among roosting locations. Temperatures were generally lowest in 2003 (Table 4), suggesting a possible threshold effect where ambient temperatures may not influence movements. The best model in 2003 was one that considered movements as constant across time, but differed by roost location (strata). During the two-week period in the summer of 2002 for HFA bats, maximum temperature was higher than in 2003 and 2005. The maximum temperatures during this time period were on average $8.1^{\circ} \mathrm{C}$ higher than 2003 and $3.1^{\circ} \mathrm{C}$ higher than 2005 (Table 4). The confidence intervals for the $\beta$ estimates for maximum temperature at LST did not include 0 for either year, suggesting that maximum temperatures also influenced movements among the 3 buildings at this site. In 2003, the maximum temperatures used to model movements at the LST buildings fluctuated more dramatically on a daily basis, but were generally lower than for 2005 (Table 4).

Ectoparasite intensities did not appear to influence whether a bat would move to a new roosting location, as implied by both model-ranking results and the $\beta$ estimates at HFA and LST for all years. In all cases, the model including $S$. occidentalis as an individual covariate was always $\leq 2 \Delta \mathrm{QAIC}_{\mathrm{c}}$ from the model with strata differences, which is expected from a covariate with little effect. However, bats at the HFA site had higher numbers of ectoparasites than the bats at the LST site (Table 4). Movement probabilities were generally higher at HFA than at LST, which is consistent with the idea that bats move more at sites with larger ectoparasite infestations. The average count of $S$. occidentalis per bat in 2003 at HFA was nearly 18 times the average for LST bats. In 2005, there were approximately six times more ectoparasites per bat at HFA than LST.

Estimates of movement probabilities among roosting locations differed by year and by site (Tables 5 and 6). Probabilities of moving among roosting locations at HFA were generally higher than probabilities of moving among buildings at LST as mentioned previously. At HFA in 2002, the most common switch was from the NE to SE roosting locations. In 2003, moving from the SE to NW had the highest probability, and in 2005, switching from the NE to NW was most common. At LST in 2003, the most common switch occurred from A (a bat box on a mobile home) to B (the house next door). In 2005, the most common switch was from the $\mathrm{C}$ house to the bat box (A).

TABLE 5. Estimates of movement probabilities $(\hat{\psi})$ and corresponding $95 \%$ confidence intervals for lactating big brown bats during two-week periods in 2002, 2003, and 2005 at the HFA building, Fort Collins, Colorado, USA.

\begin{tabular}{lccccc}
\hline \hline Estimate & Year & $\hat{\psi} \mathrm{NE}$ & $\hat{\psi} \mathrm{NW}$ & $\hat{\psi} \mathrm{SE}$ & $\hat{\psi} \mathrm{SW}$ \\
\hline$\hat{\psi} \mathrm{NE}$ & 2002 & $0.49(0.33-0.64)$ & $0.05(0.01-0.19)$ & $0.42(0.28-0.58)$ & $0.04(0.01-0.18)$ \\
& 2003 & $0.81(0.77-0.85)$ & $0.08(0.05-0.11)$ & $0.03(0.01-0.11)$ & $0.08(0.06-0.12)$ \\
$\hat{\psi} \mathrm{NW}$ & 2005 & $0.18(0.09-0.26)$ & $0.82(0.60-0.93)$ & 0.00 & 0.00 \\
& 2002 & $0.10(0.04-0.24)$ & $0.57(0.42-0.70)$ & $0.27(0.16-0.42)$ & $0.06(0.001-0.04)$ \\
& 2003 & $0.25(0.18-0.33)$ & $0.63(0.55-0.71)$ & $0.01(0.003-0.06)$ & $0.11(0.06-0.17)$ \\
$\hat{\psi} \mathrm{SE}$ & 2005 & $0.04(0.03-0.07)$ & $0.77(0.68-0.80)$ & $0.02(0.01-0.04)$ & $0.17(0.13-0.20)$ \\
& 2002 & $0.005(0.001-0.04)$ & $0.03(0.01-0.07)$ & $0.76(0.69-0.81)$ & $0.21(0.16-0.27)$ \\
& 2003 & $0.21(0.08-0.46)$ & $0.38(0.18-0.62)$ & $0.16(0.05-0.40)$ & $0.25(0.10-0.50)$ \\
$\hat{\psi} \mathrm{SWW}$ & 2005 & 0.00 & $0.21(0.08-0.42)$ & $0.66(0.58-0.75)$ & $0.13(0.04-0.36)$ \\
& 2002 & $0.01(0.002-0.08)$ & $0.12(0.07-0.21)$ & $0.16(0.09-0.25)$ & $0.71(0.60-0.79)$ \\
& 2003 & $0.06(0.03-0.11)$ & $0.18(0.12-0.26)$ & $0.03(0.01-0.08)$ & $0.73(0.65-0.80)$ \\
& 2005 & 0.00 & $0.09(0.07-0.12)$ & $0.002(0.0003-0.02)$ & $0.91(0.72-0.97)$ \\
\hline
\end{tabular}

Notes: NE, NW, SE, and SW were the four strata (roost locations) used. Model $\Psi(s)$ was used to estimate the probability of moving (Table 2). Read across rows for probabilities of movement between two strata (i.e., daily probability of moving from NE to SE in 2002 was 0.42 , and probability of moving from NW to SE in 2005 was 0.02 ). 
TABLE 6. Estimates of movement probabilities $(\hat{\psi})$ and corresponding $95 \%$ confidence intervals for lactating big brown bats during two-week periods in 2003 and 2005 at the LST complex of buildings, Fort Collins, Colorado, USA.

\begin{tabular}{ccccc}
\hline \hline Estimate & Year & $\hat{\psi} \mathrm{A}$ & $\hat{\psi} \mathrm{B}$ & $\hat{\psi} \mathrm{C}$ \\
\hline$\hat{\psi} \mathrm{A}$ & 2003 & $0.68(0.42-0.86)$ & $0.25(0.10-0.49)$ & $0.07(0.02-0.25)$ \\
& 2005 & $0.86(0.79-0.89)$ & $0.03(0.01-0.06)$ & $0.12(0.08-0.17)$ \\
$\hat{\psi} \mathrm{B}$ & 2003 & $0.18(0.10-0.30)$ & $0.74(0.62-0.83)$ & $0.08(0.03-0.17)$ \\
& 2005 & $0.10(0.05-0.19)$ & $0.84(0.74-0.91)$ & $0.06(0.02-0.15)$ \\
$\hat{\psi} \mathrm{C}$ & 2003 & $0.06(0.02-0.16)$ & $0.18(0.11-0.29)$ & $0.75(0.63-0.84)$ \\
& 2005 & $0.27(0.18-0.39)$ & $0.08(0.04-0.15)$ & $0.65(0.53-0.75)$ \\
\hline
\end{tabular}

Notes: A, B, and C were the three strata (roost locations) used. Model $\Psi(s)$ was used to estimate the probability of moving (Table 3 ). Read across rows for probabilities of movement between two strata.

\section{DiscusSION}

Our findings suggest that periods with unusually hot conditions are accompanied by increased shifting of female big brown bats to different buildings or segments of buildings. This might increase the potential for contact with people in settings where, in comparison to their more regularly used buildings, bats may be more likely to be of public concern as nuisances or health risks. A management strategy of waiting in the short term for conditions to change and for bats to shift away, then sealing entrances after bats have left may be favorable both for bat conservation and to reduce risks of future public contact and potential disease exposure. Additional research is needed to determine how commonly bats come to the attention of public health or animal control authorities during periods of high daily temperatures.

Studies that quantify mechanisms promoting roost switching or movements of bats among roosts are rare and have relied on radio-tracking of a limited number of individuals over short periods of a few days time (Lewis 1996, Willis and Brigham 2004). With the recent availability of PIT tags and readers, we have shown that it is now possible to passively track bats using multiple roosts simultaneously, use these data to construct daily encounter histories, and use multi-state, mark-recapture models to quantify survival, capture, and movement probabilities (probabilities associated with roost switching). The results of our analyses indicated that considerable movement occurred by female big brown bats among roosting locations in buildings at two sites in Fort Collins, Colorado. Movements occurred on a daily basis and during the critical period when bats were lactating. Although this was not determined, bats may have been carrying their young to new roosting locations, an energetically costly and potentially risky activity. Our data suggest that high ambient temperatures influenced movements for most sites and years. The only case where temperature did not appear to influence movements was during the 2003 lactation period at the HFA building site. In this case, the probabilities of moving to a new location were best explained using the model with movements varying by strata (location) alone. Ectoparasite loads did not appear to influence movements of bats during lactation within each site. Since we only investigated movement probabilities during a two-week period at one stage of reproduction, our results are biased toward that time period. Movements of bats among buildings could differ through the summer and at different stages of reproduction.

Roost switching in big brown bats is common and descriptive studies have suggested it may vary in frequency depending on geographic location, roosting structures, and reproductive status (Brigham 1991, Kalcounis and Brigham 1998, Lausen and Barclay 2002, 2003, Willis and Brigham 2004). Brigham (1991) suggested that availability of roosting structures could explain why roost fidelity varies geographically for big brown bats. In rural Ontario, he argued that bats roosting in buildings were site faithful because buildings were rare, whereas, in British Columbia, bats roosting in tree cavities switched roosts frequently because they were abundant. Kalcounis and Brigham (1998) found that big brown bats roosting in aspen cavities in Saskatchewan remained faithful to a particular group of trees, but would switch frequently among them. Lausen and Barclay (2002, 2003) studied big brown bats roosting in rock crevices in southeastern Alberta, Canada. They found that adult females switched roosts frequently, and they suggested that selection of crevices by these bats was based on microclimate and avoidance of predation. Roost switching by this population of big brown bats also varied in frequency depending on reproductive status and propensity for using torpor: pregnant and lactating bats moved more than postlactating bats. In our study, we also found frequent roost switching on a daily basis among buildings similar to studies of big brown bats roosting in trees and rock crevices. We attribute shifting of roosts to temperature fluctuations, and corresponding responses of the bats. Our findings are consistent with the hypothesis that roost switching by bats plays a role in a fission-fusion model of social organization, with an ultimate selective advantage being the promotion of social cohesion among colony members within a small area encompassing several alternative roosts (Willis and Brigham 2004). We suggest that in addition to this ultimate advantage, 


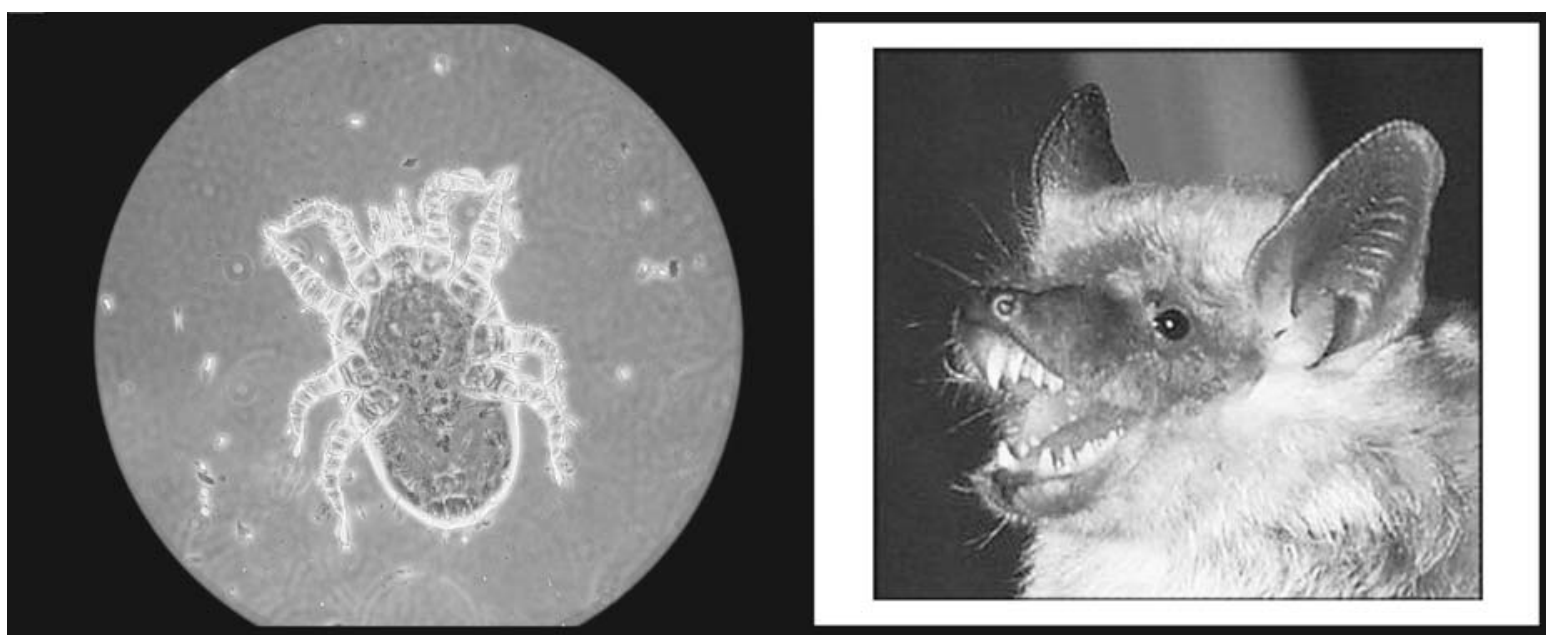

Plate 1. Protonymph stage of the macronyssid mite, Steatonyssus occidentalis (left, magnification 100×; photo credit: Roger D. Pearce). This was an abundant ectoparasite on the big brown bat, Eptesicus fuscus (right; photo credit: R. A. Bowen) roosting in buildings in Fort Collins, Colorado.

temperature shifts are an important proximate mechanism stimulating such moves.

Temperature within and outside of roosts is important to bats because they spend a significant part of their lives within these structures (Kunz 1982). For species of bats that roost in small crevices or cavities, previous studies have suggested that lability in occupancy of roosts may be a response to ambient temperature fluctuations. Davis et al. (1968) found that big brown bats will move from roosting locations, perhaps even abandoning the colony site, when ambient temperature exceeds $33-35^{\circ} \mathrm{C}$. We found that more bats moved among roosting locations in 2002 when the average maximum ambient temperature was $31.2^{\circ} \mathrm{C}$ and four out of the 14 days had maximum daily temperatures exceeding $33^{\circ} \mathrm{C}$. Although we did not measure internal roost temperatures during the three years used for these analyses, we did measure temperatures within the roosts at the two sites in 2004. Internal roost temperatures in the four strata at HFA were, on average, $8-10^{\circ} \mathrm{C}$ higher than ambient temperatures, and at LST, internal temperatures in the three strata were on average $5-10^{\circ} \mathrm{C}$ higher. These higher temperatures within the roost than outside were presumably due to direct insolation and heat retention in attics and between walls. There was generally less movement and bats used fewer roost locations in 2003 and 2005 when maximum daily temperatures never exceeded $33^{\circ} \mathrm{C}$ during the two weeks movements were monitored. The lower probabilities of movement at the LST buildings may reflect a wider gradient of temperatures available to bats within attics of two of these buildings than within the walls at HFA; ectoparasite counts were also markedly lower at these roosts, and the model incorporating maximum temperature ranked highest in each of the summer sampling periods.

Ectoparasites may reduce fitness of their hosts by affecting either survival or reproductive success; hence, it is favorable to evolve host behavioral defenses. For bats, ectoparasite densities within a roost or on individual bats have been implicated in choice of roost (Lewis 1993, ter Hofstede and Fenton 2005). We chose $S$. occidentalis mites to model movements because they were the most abundant ectoparasite we found. Dood (1987) found this for big brown bats in northwestern Ohio as well. S. occidentalis principally dwell in the roost and only occur on bats for feeding on blood and perhaps mating (Dood 1987). Large infestations of these mites on female and juvenile bats in colonies have the potential to negatively impact hosts through irritation, stress, blood loss, and energy loss through grooming (Keen and Hitchcock 1980, Dood 1987). Despite these potential detriments and suggestions in the literature that ectoparasites may influence roost switching in bats (Lewis 1996, Lausen and Barclay 2002), we found little evidence that $S$. occidentalis prevalence at the levels we observed, influenced lability in movements among roosting locations within a site by bats. However, ectoparasite loads were higher at HFA, which may explain why bats moved more at this site compared to LST. And, it is possible that the strong evidence for temperature fluctuations influencing movements during the two-week periods examined masked the effects of mites on bat movements.

\section{ACKNOWLEDGMENTS}

Financial support for this work was provided via NSF Grant \#0094959 to Colorado State University. We thank D. Anderson, R. Reich, T. Stanley, and C. Rupprecht for input to study planning. G. White provided invaluable assistance with Program MARK. S. Almon, J. Ammon, T. Barnes, J. Boland, L. Bonewell, S. Cooper, T. Dawes, M. Hayes, B. Iannone, E. Kennedy, R. Kerscher, J. LaPlante, G. Nance, S. Neils, V. Price, C. Reynolds, L. Taraba, and J. Tharp assisted in fieldwork during 2002-2005. R. Pearce identified ectoparasites and guided their counting. T. Stanley, G. White, M. Brigham, 
and an anonymous reviewer provided helpful comments on earlier versions of this manuscript.

\section{Literature Cited}

Brigham, R. M. 1991. Flexibility in foraging and roosting behaviour by the big brown bat (Eptesicus fuscus). Canadian Journal of Zoology 69:117-121.

Brigham, R. M., and M. B. Fenton. 1986. The influence of roost closure on the roosting and foraging behaviour of Eptesicus fuscus (Chiroptera: Vespertilionidae). Canadian Journal of Zoology 64:1128-1133.

Brownie, C., J. E. Hines, J. D. Nichols, K. H. Pollock, and J. B. Hestbeck. 1993. Capture-recapture studies for multiple strata including non-Markovian transitions. Biometrics 49:11731187.

Burnham, K. P., and D. R. Anderson. 2002. Model selection and multimodel inference: a practical information-theoretic approach. Second edition. Springer-Verlag, New York, New York, USA.

Cormack, R. M. 1964. Estimates of survival from the sighting of marked animals. Biometrika 51:429-438.

Davis, W. H., R. W. Barbour, and M. D. Hassell. 1968. Colonial behavior of Eptesicus fuscus. Journal of Mammalogy 49:44-50.

Dood, S. B. 1987. Acari associated with Eptesicus fuscus (Chiroptera: Vespertilionidae) in northwestern Ohio. Dissertation. Bowling Green State University, Bowling Green, Ohio, USA.

Hestbeck, J. B., J. D. Nichols, and R. A. Malecki. 1991. Estimates of movement and site fidelity using mark-resight data of wintering Canada geese. Ecology 72:523-533.

Jolly, G. M. 1965. Explicit estimates from capture-recapture data with both death and immigration stochastic model. Biometrika 52:225-247.

Kalcounis, M. C., and R. M. Brigham. 1998. Secondary use of aspen cavities by tree-roosting big brown bats. Journal of Wildlife Management 62:603-611.

Keen, R., and H. B. Hitchcock. 1980. Survival and longevity of the little brown bat (Myotis lucifugus) in southeastern Ontario. Journal of Mammalogy 61:1-7.

Kunz, T. H. 1982. Roosting ecology of bats. Pages $1-55$ in T. H. Kunz, editor. Ecology of bats. Plenum Press, New York, New York, USA.

Kunz, T. H., and L. F. Lumsden. 2003. Ecology of cavity and foliage roosting bats. Pages 3-89 in T. H. Kunz and M. B. Fenton, editors. Bat ecology. University of Chicago Press, Chicago, Illinois, USA.

Kunz, T. H., and D. S. Reynolds. 2003. Bat colonies in buildings. Pages 91-102 in T. J. O'Shea and M. A. Bogan, editors. Monitoring bat populations in the United States and territories: problems and prospects. U.S. Geological Survey Information and Technology Report ITR 2003-0003. U.S. Geological Survey, Washington, D.C., USA.

Kurta, A., and R. H. Baker. 1990. Eptesicus fuscus. Mammalian Species 356:1-10.

Lausen, C. L., and R. M. R. Barclay. 2002. Roosting behaviour and roost selection of female big brown bats (Eptesicus fuscus) roosting in rock crevices in southeastern Alberta. Canadian Journal of Zoology 80:1069-1076.

Lausen, C. L., and R. M. R. Barclay. 2003. Thermoregulation and roost selection by reproductive female big brown bats (Eptesicus fuscus) roosting in rock crevices. Journal of Zoology, London 260:235-244.

Lebreton, J. D., K. P. Burnham, J. Clobert, and D. R. Anderson. 1992. Modeling survival and testing biological hypotheses using marked animals: a unified approach with case studies. Ecological Monographs 62:67-118.

Lewis, S. E. 1993. Effect of climatic variation on reproduction by pallid bats (Antrozous pallidus). Canadian Journal of Zoology 71:1429-1433.

Lewis, S. E. 1995. Roost fidelity of bats: a review. Journal of Mammalogy 76:481-496.

Lewis, S. E. 1996. Low roost-site fidelity in pallid bats: associated factors and effect on group stability. Behavioral and Ecological Sociobiology 39:335-344.

Mayrberger, S. 2003. Exit/entry sequences, roost fidelity and transport of young by big brown bats (Eptesicus fuscus) at a summer roost. Thesis. University of Michigan, Flint, Michigan, USA.

Mondul, A. J., J. W. Krebs, and J. E. Childs. 2003. Trends in national surveillance for rabies among bats in the United States (1993-2000). Journal of the American Veterinary Medical Association 222:633-639.

O'Shea, T. J., L. E. Ellison, and T. R. Stanley. 2004. Survival estimation in bats: historical overview, critical appraisal, and suggestions for new approaches. Pages 297-336 in W. L. Thompson, editor. Sampling rare or elusive species: concepts, designs, and techniques for estimating population parameters. Island Press, Washington, D.C., USA.

Pape, J. W., T. D. Fitzsimmons, and R. E. Hoffman. 1999. Risk for rabies transmission from encounters with bats, Colorado, 1977-1996. Emerging Infectious Diseases 5:433-437.

Racey, P. A. 1982. Ecology of bat reproduction. Pages 57-103 in T. H. Kunz, editor. Ecology of bats. Plenum Press, New York, New York, USA.

Seber, G. A. F. 1965. A note on the multiple recapture census. Biometrika 52:249-259.

ter Hofstede, H. M., and M. B. Fenton. 2005. Relationships between roost preferences, ectoparasite density, and grooming behaviour of neotropical bats. Journal of Zoology, London 266:333-340.

White, G. C., and K. P. Burnham. 1999. Program MARK: survival estimation from populations of marked animals. Bird Study 46(Supplement): $120-138$.

Williams, L. M., and M. C. Brittingham. 1997. Selection of maternity roosts by big brown bats. Journal of Wildlife Management 61:359-368.

Willis, C. K. R., and R. M. Brigham. 2004. Roost switching, roost sharing and social cohesion: forest-dwelling big brown bats, Eptesicus fuscus, conform to the fission-fusion model. Animal Behaviour 68:495-505.

Wimsatt, J., T. J. O'Shea, L. E. Ellison, R. D. Pearce, and V. R. Price. 2005. Anesthesia and blood sampling of wild big brown bats (Eptesicus fuscus) with an assessment of impacts on survival. Journal of Wildlife Diseases 41:87-95. 